\title{
TRAJETÓRIA DO MOVIMENTO ESTUDANTIL E EXPECTATIVAS SOCIAIS DOS ESTUDANTES BRASILEIROS: 1960-1980
}

\author{
Ruy H. de Araújo Medeiros * \\ Sérgio Castanho ${ }^{* *}$
}

\section{RESUMO}

O presente artigo apresenta a trajetória do movimento estudantil no Brasil, desde a década de 1960 até o final da década de 1980, com ênfase no período do Golpe Militar, enfocando a atuação dos estudantes, sua organização como classe estudantil, suas inúmeras facções, militância, a perseguição sofrida e, maiormente, suas expectativas e reações ao estado ditatorial. O texto contextua aspectos econômicos, políticos e sociais do período enfocado, os atos institucionais e arbitrariedades impostas pelo regime e pontua os principais episódios nos quais os estudantes foram atores principais e ou coadjuvantes na reação à ditadura instaurada. Para tanto, à luz da história e da memória, a literatura mais importante sobre tal temática foi revisada, leis e decretos foram analisados e procedeu-se a uma exaustiva pesquisa em jornais, revistas e outras formas midiáticas veiculadas antes, durante e depois desses acontecimentos.

Palavras-chave: História, Movimento Estudantil, Golpe Militar, 1964.

\section{ABSTRACTS}

This article presents the history of the student movement in Brazil from the 1960s until the late 1980s, with emphasis on the period of the Military Coup, focusing on the performance of students, their organization as student class, their many factions, militancy, the persecution and, mainly, their expectations and reaction to the dictatorial state. The article demonstrates economic, political and social aspects of the focused period, and institutional and arbitrary acts, imposed by the regime and punctuates the main episodes in which students were the main actors and supporting actors in reaction to the established dictatorship. For both, guided by the history and memory, the most important of such literature was reviewed: laws and decrees were analyzed, further on, an extensive search in newspapers, magazines and other media ways from before, during and after these events.

Key Words: History - Student Movement - Military Coup - 1964

\section{DE JK AO GOLPE DE ESTADO}

Entre 1956 e 1964, o movimento estudantil no Brasil atingiu nível de atuação e de influência política acentuado, sobretudo no primeiro quinquênio dos anos $60{ }^{1}$

A União Nacional dos Estudantes (UNE) crescera em grau de representatividade e o programa, material, propostas e manifestos de seus congressos, abarcavam gama variada de preocupações: desde a solidariedade com os "povos oprimidos" da Ásia, África e América Latina até a luta pela defesa da "cultura nacional". A preocupação com a atividade político-social era uma marca do movimento organizado dos estudantes. A luta pela autodeterminação das antigas colônias da Ásia e da África, intensificada neste último continente nas décadas de 1950 e 1960, era exaltada pelo movimento estudantil brasileiro, ao mesmo tempo em que este lutava por mais vagas e mais verbas para a educação. 
O movimento ganhou corpo e esteve presente na luta pela posse de João Goulart; depois, a favor da volta ao presidencialismo e, mais tarde, aliada à proposta das "reformas" de base. Os conteúdos das propostas do movimento, aqui e ali, denotavam a inquietação reformista.

No bojo da crise econômica, que sobreveio após fase de expansão da economia com Juscelino Kubitschek (JK), os estudantes marcavam presença no cenário nacional. A UNE não vivia apenas das passeatas ou dos congressos; não apenas participava de comícios, mas envolvia-se na produção e difusão cultural, como se pode atestar com o trajeto do Centro Popular de Cultura - CCPC, experiência que ligou intelectuais de vanguarda ao movimento estudantil, num processo de auto alimentação. (MARTINS, 1980) ${ }^{2}$

Deste tempo é a UNE VOLANTE ${ }^{3}$, a greve de 1/3, o Congresso de Reforma Universitária, dentre outros eventos. Também não se pode esquecer a participação da UNE no congresso Camponês ${ }^{4}$ e na Frente de Mobilização Popular (REIS FILHO E SÁ, 1985; LIMA e ARANTES, 1984) . $^{5}$.

Disputavam a hegemonia do movimento, e da UNE, por conseguinte, o PCB, PC do B (depois de 1962), a Política Operária (POLOP), Organização Revolucionária Política Operária (ORMPO), a Juventude Operária Católica (JUC) ${ }^{6}$ e, depois (1963) a Ação Popular $(\mathrm{AP})^{7}$, que se expressavam com propostas específicas. A dominância, no seio do Movimento Estudantil - ME (doravante ME) era reformista. A chamada "esquerda festiva" ocupava muito espaço de participação na UNE.

\section{DEPOIS DO GOLPE}

Em 13 de março de 1964, no famoso comício pelas "reformas de base", a UNE usou da palavra. Pronunciou-se pelas mudanças propostas, ao lado do bloco que se formava em torno de alterações preconizadas para tirar da estagnação o país. O movimento estudantil se torna uma das principais frentes de oposição ao regime.

Era um movimento de culminância.

Em 31 de março, no entanto, começa nova vida. O Golpe Militar (1964) inicia período de repressão política só comparável ao da Ditadura Vargas, em nosso país. É durante os primeiros anos do regime militar implantado que depois de desorganizada a oposição política institucionalizada (dissolução dos partidos políticos, cassação de mandatos, etc.), depois de "pacificado" o movimento operário (grandemente controlado antes por reformistas), vencida a oposição militar, os estudantes continuaram na luta, pode se dizer...

A UNE foi posta na clandestinidade, considerada ilegal e sua sede foi incendiada ${ }^{8}$.

Desde antes do golpe, os grupos de direita já promoviam campanha contra a UNE. Em 1962, por exemplo, o Jornal do Brasil publicara uma série de reportagens sob o título "UNE, Menina dos olhos do PC", e em 1963 o IPES financiou o livro "UNE Instrumento de subversão" (as reportagens, assim como o Livro, são de autoria de Sônia Maria Saraiva Seganfreddo).

A UNE passou a atuar num ambiente difícil: opressão política, de um lado; momento de crise das esquerdas, por outro. O "populismo" começava a ser posto em questão, tanto pela direita quanto pela esquerda. A UNE torna-se canal de manifestação de diversas camadas que se opunham ao regime, mas que estavam sem condições de se manifestar.

Movimentos como a setembrada (1966), conjunto de manifestações contra a repressão, foram liderados pela UNE. Pode-se dizer, com alguma ressalva que do ponto de 
vista do combate ao regime militar, o movimento estudantil tornou-se canal único de participação. É curioso mesmo que este ponto tenha sido recentemente lembrado por um dos mais ativos participantes do Movimento Estudantil (ME), José Dirceu, que acredita que a "UNE acabou se tornando um canal de representação para os setores descontentes das camadas médias da população. Neste último ponto - diz José Dirceu ${ }^{10}$ - reside a principal diferença entre o movimento estudantil de hoje e aquele onde eu atuava. Hoje os sindicatos estão fortes, as associações de bairro também e o jovem pode participar de todas estas entidades. O movimento estudantil não é mais o único canal de participação".

As organizações de esquerda atuavam bastante no movimento estudantil e até podese dizer que algumas delas "nasceram no ME", como é o caso da AP, criada em 1963, em Salvador, a partir da ala esquerda da JC, e da OC $1^{\circ}$ de Maio, fundada a partir do "ME $1^{\circ}$ de Maio" (1968) ${ }^{11 .}$.

A ascensão do movimento estudantil não se tornou apenas um fator para a divulgação de propostas da esquerda, como também esta passou a elaborar táticas específicas para o movimento estudantil (caso da AP, PC do B, PCB, etc.) e os partidos criados na época (MDP e ARENA) passaram a ter previsão de departamentos jovens em seus estatutos ${ }^{12}$.

No período, pode-se dizer que os estudantes de esquerda tinham expectativas sociais referenciadas nos programas dos principais grupamentos onde atuavam.

É evidente que o movimento estudantil passou a sofrer o impacto do golpe, de toda a reordenação econômico-institucional proposta e implementada pela ditadura militar ${ }^{13}$.

Tendo ocupado plenamente o poder, apesar das resistências, que espocavam aqui e ali, os militares e tecnocratas começaram a preparar o ciclo de nova expansão (novo ciclo de acumulação capitalista). Para isso, montaram política salarial de arrocho; reorganizaram o sistema bancário; implementaram organismo para cuidar da habitação; sistematizaram meios e instrumentos para captação de poupança; adotaram mecanismos para crescimento da indústria pesada e da agricultura; concentraram a renda...

Os diversos mecanismos iriam dar no "milagre brasileiro", que se funda genericamente, em um tripé: arrocho salarial (com aumento da massa de mais valia), abertura externa da economia (incentivo às exportações, atração de investimentos externos, inclusive de expansão das multinacionais nos país), e expansão do crédito.

A nova política intensifica a monopolização da economia e a concentração da renda. Em derredor disso, expandiu-se a burocracia (estatal e particular). Para alguns, a monopolização significa o fim de possibilidade de ascensão social através de atividades econômicas de pequeno porte e, portanto, a educação é vista como possibilidade de ascensão aos postos privilegiados da burocracia (executivos bem pagos, vizinhança do poder); para outros, as mudanças trazem expectativas de ascensão, via educação, tendo em vista as necessidades do mercado (porém, para conseguir ascensão é necessário o ensino gratuito, de bom nível e com escolas dotadas de boas estruturas, capazes de garantirem a expansão sempre).

Luís Antonio Rodrigues da Cunha $(1973)^{14}$ estabelece um paralelo entre a política do "milagre", as expectativas dos estudantes (classe média) e a reforma universitária:

[...] a partir de 1968: a mudança do modelo de ascensão das camadas médias. Anteriormente, este passava pela constituição de capital, através da poupança, investimento em pequenas empresas, reprodução do capital, nova poupança, etc. O alvo da ascensão social para as camadas médias era a abertura de um pequeno negócio ou o exercício de uma atividade profissional por conta própria. A partir desse processo de concentração de capital, renda e mercado, no entanto, os canais "tradicionais" de ascensão 
tornam-se cada vez mais estreitos. Em função disso, as alternativas de ascensão das camadas médias, transferem-se para as hierarquias ocupacionais, que se ampliam e multiplicam, tanto no setor privado quanto no setor público da economia (1973, p.45).

E mais:

Ora a disputa por promoção no interior das hierarquias ocupacionais envolverá gastos maciços em escolarização e/ou a reivindicação de subvenções públicas para o ensino. Já a partir da década de 50, desse modo, verificou-se um crescimento cada vez mais intenso da demanda por escolarização. A conquista de graus escolares mais e mais elevados não garante, mas permite que se postule $\mathrm{z}$ ascensão social nessa nova fase.

Em 1964, as camadas médias receberam um prêmio, uma recompensa pelo seu apoio político às mudanças havidas: aumento intenso das vagas no ensino superior. A política adotada posteriormente, no entanto, acelerou o processo de concentração em curso [idem].

O autor, prossegue, afirmando que, apesar de haver apoiado o golpe, num momento posterior as "classes médias" seriam prejudicadas, via política econômica e política educacional, por ação do Estado que ajudaram a implantar. No segundo período, com a não expansão continuada da oferta de vagas/escolas superiores, surgem as duas grandes reivindicações: mais verbas e mais vagas ${ }^{15}$.

Ora, o atendimento de expectativas pessoas, diante do novo quadro de fechamento, impunha uma combinação de atuação em vista de expectativas sociais: a expansão do ensino, uma universidade capaz de formar quadros respeitáveis, com mais verbas e melhor ensino (ao invés de uma universidade órfã), uma política geral capaz de conciliar as expectativas individuais com a possibilidade de implementação destas, fato que induzia à critica às empresas multinacionais, à concentração de renda, à política econômica, ao questionamento político.

O movimento era contraditório: ele acenava com a possibilidade de ascensão via educação, mas acenava com a limitação a esse canal de enriquecimento à medida que controlava e que mesmo parecia priorizar a formação técnica de nível médio, além de que deixou de drenar recursos suficientes para a expansão do ensino superior público.

A ação estudantil passa a movimentar-se num processo de mediação de expectativas individuais com expectativas sociais e, muitas vezes, para grupos significativos de estudantes, estas prevaleceram e estiveram insistentemente no debate político $^{16}$.

O que se quer dizer é exatamente que as lutas por mais verbas, mais vagas, ensino público e gratuito, contra a privatização, e similares, conseguem mediar expectativas socais (políticas, democráticas) com expectativas individuais (possibilidade de a pessoa educarse, poder ascender etc.). Quando a crítica vai mais adiante, porque o regime não deixou canais de expressão e porque toda a população (inclusive os estudantes) passou a sofrer efeitos da concentração da renda, a radicalização dos estudantes no questionamento de toda a realidade se impôs.

Um momento privilegiado para verificar aquelas expectativas sociais (para que se complemente o ideário dos partidos de esquerda presentes no ME) é o da discussão da "Reforma Universitária". No contexto da discussão desta, os estudantes repudiaram os "Acordos Mec-Usaid" e o "Relatório Atcon". Greves imensas sucederam-se. Na Bahia, foi realizado o II SERU. Estudo de Ted Goertzel (bolsista norte-americano) sobre o 
significado dos "Acordos Mec-Usaid" tornou-se um referencial bastante usado pelos estudantes para repudiarem a reforma proposta (em gestação) pela ditadura ${ }^{17}$.

Os estudantes dividiam-se quanto à reforma. Primeiro, dividiram-se quanto a "ir" ou "não ir" para o "diálogo" proposto pelo Ministro da Educação (1967/68). Depois, dividiram-se quanto á reforma do ensino, ao seu caráter e conteúdo. E cada grupo passou a defender seu projeto de universidade, a partir "das necessidades do povo brasileiro", das camadas "médias e das camadas oprimidas da população", etc.

Uns adotavam a consigna de "Universidade Livre, Democrática e Progressista"; outros acenavam com a palavra de ordem de "Universidade Popular, Autônoma e Democrática"; outros reivindicavam uma "Universidade Livre" e, ainda outro grupo falava em "Universidade Crítica". Todas estas propostas indicavam a necessidade de uma Universidade que preservasse sua autonomia, estivesse referenciada nos interesses do povo brasileiro, que garantisse a liberdade de ensino. As justificativas passavam por uma análise da sociedade, um programa social e a universidade necessária a esse programa que, inclusive, garantisse o acesso às classes pobres e voltada para a resolução dos problemas sociais do Brasil ${ }^{18}$.

O ano de 1968 foi um marco. Foi o momento de grandes lutas de jovens, no Brasil e no mundo. A passeata dos Cem Mil, no Rio de Janeiro, após o assassínio do Estudante Edson Luís Lima Souto, foi fato político de relevância impar. A ditadura apertou mais ainda o cerco. Relatórios de serviço de segurança passaram a identificar correntes políticas e seus métodos de atuação, além de sua forma de organização, no ME.

Em 1969, o endurecimento completou-se: foi editado o Decreto 477, a fim de expulsar os estudantes e professores de esquerda das escolas secundárias e superiores. Já no ano anterior, mais de 1.000 estudantes foram presos, em Ibiúna, São Paulo, quando se preparavam para a realização do XXX Congresso da Une.

Movimentos de protestos desenvolveram-se em vários lugares e a principal palavra de ordem era: "Abaixo a Ditadura". Mas o regime militar conseguiu impor-se e impor sua reforma. O movimento estudantil e todo o movimento de esquerda começaram a ser perseguidos ferozmente, caçados com fúria. $\mathrm{Na}$ adversidade total, o $\mathrm{ME}$ ainda tentou sobreviver depois do AI 5 e do Decreto 477, mas já para denunciar com mais afinco os crimes de morte e as torturas de presos políticos, muitos dos quais estudantes.

Veio o refluxo. O silêncio - doloroso e marcante. Ainda em 1973, deputado liberal, vinculado à oposição, produziu um discurso com título a um só tempo triste e sugestivo: "O estudante morreu". ${ }^{19}$.

Mas, o refluxo não era a morte, como se pode ver no período subsequente em que o movimento estudantil aos poucos vai refazendo-se. Tarefa difícil. Mesmo alguns setores ditos liberais, que passaram a beneficiar-se da política do "milagre" amainaram suas críticas, calaram-se mesmo - para só com a crise nova que atingiria a economia voltarem a falar em democracia.

\section{APÓS O MILAGRE}

O momento seguinte ao AI 5/ 477 foi um tempo em que os estudantes tentaram ainda "segurar" suas entidades, mas estas foram gradativamente caindo em mãos da direita - estudantes vinculados às diretorias das faculdades e institutos, defensores da ditadura. Porém, aqui e ali, percebia-se que algo ainda vivia, com dificuldade. A partir de 1971/1972, o movimento estudantil engatinhava na busca da retomada. Várias entidades foram reconquistadas à direita, passaram a ser realizados "encontros de cursos", debates, 
etc. Em 1974, contrariando as normas vigentes, ocorreram eleições diretas para vários DCEs. Em 1975, foi realizado o I Encontro Nacional de Estudantes (I ENE), sob grandes dificuldades e com limitações; no ano seguinte, igual evento ocorreria e - como marco foi criado o DCE LIVRE da USP (1975). As "residências" de estudantes passaram a funcionar, timidamente, como entidades representativas de tal ou qual grupo.

O Movimento estudantil retomava seu curso.

A partir de 1973, o conjunto de medidas de política econômica que fizeram aflorar o "milagre" já não encontrava mais oportunidade de aplicação. Apesar de ainda gozar da entrada de capitais estrangeiras, em 1973, e de bom nível de reservas cambiais, logo o país passou a encontrar condições adversas para manter seu crescimento acelerado e com inflação em índices baixos. Em 1974, o balanço de pagamento se desequilibrou e o déficit foi espantoso: US\$ 5 bilhões. Este fato está ligado, em parte apenas, à chamada crise do petróleo, que determinou aumento do valor das importações brasileiras (o barril de petróleo aumentou bastante de preço) e, também, à forte importação de insumos ${ }^{20}$.

Isso ocorreu quando nova recessão atingiu os países desenvolvidos, que reprimiram compras a outros, inclusive ao Brasil, e quando o mercado financeiro internacional não estava em condições de fornecer maiores empréstimos. A inflação ${ }^{21}$ retomou sua escalada. Embora a economia ainda crescesse, a crise instalava-se.

Com o fim do "milagre" a instalação de crise, a sociedade foi mudando. Politicamente, a oposição cresceu bastante nas eleições de novembro de 1974 (LAMOUNIER, 1974) ${ }^{22}$.

A sociedade brasileira começou a atravessar um novo processo de "emergência" de vários setores: os trabalhadores, sob imensas dificuldades, rompendo obstáculos, voltaram a criar comissões de fábrica ${ }^{23}$, comitês de empresas, oposições sindicais e, em continuidade, fundos de greve, num processo que iria explodir nas greves de 1978 e 1979, na manutenção de fundo de greve e na criação de centrais sindicais, depois.

No âmbito da Igreja, as comunidades eclesiais de base despontavam, e setores católicos passavam a se expressar num movimento que já foi chamado de "reinvenção da participação popular" (NASCIMENTO, 1985) ${ }^{24}$. Enquanto isso, associações de bairro proliferavam-se nas cidades, patrocinando movimentos nas periferias urbanas.

Nas universidades, igualmente, sem maior programa expresso, o movimento vai-se ativando aos poucos, conforme já foi mencionado.

À reconquista de entidades à direita, à implementação de eleições diretas para vários DCEs, à criação do DCE Livre da USP e à realização do I e II ENEs, sucederam-se outros fatos. Aqui e ali, em cada curso, passaram a despontar DAs livres, exposições, discussões sobre universidade, até que, em 1977, ocorreu a greve da PUC/RIO, contra o aumento de anuidades (29 de março), surgiu a passeata, em SP, por mais verbas e melhores condições de ensino (30 de março), ocorreram novas passeatas, em SP, contra a prisão de estudantes e trabalhadores, greve geral dos estudantes da UNB, em protesto contra punição de colegas que, em 31 de maio, participaram do "Dia Nacional de Luta pela Anistia"; tentativa de realização do III ENE, em Belo Horizonte, quando foram presos 800 estudantes (4 de junho), greve na UNB (16 de junho), novas passeatas em São Paulo (15 de junho), greve na USP em solidariedade aos estudantes expulsos da UNB (em 3 de agosto); passeatas em São Paulo, Porto Alegre, Campinas e Salvador, em 23 de agosto, por liberdades democráticas, realização do III ENE, clandestinamente, na PUC/SP, em 22 de setembro, quando foi criada a comissão pró-reconstrução da UNE.

O ano de 1978 foi marcado por passeatas e manifestações em muitas cidades do país, em homenagem a Edson Luís Lima Souto ${ }^{25}$ (assassinado em 28.03.68) e a Alexandre Vanucchi Leme ${ }^{26}$ (estudante também assassinado pela polícia), e pela realização, em 
setembro, do IV ENE, que definiu a realização do XXXI Congresso da UNE para o ano seguinte e o apoio eleitoral aos candidatos populares do MDB.

Era a retomada do movimento, sem dúvida, no processo de emersão da própria universidade e do conjunto de setores da sociedade civil. E, efetivamente, no seio da universidade $^{27}$, a inquietação reinstalou: não só os alunos recomeçaram a luta, mas os professores, como nunca, passaram a mobilizar-se. Não só a luta salarial, mas a questão de currículos, o respeito às decisões departamentais etc., e, principalmente, um conjunto de reflexões sobre o ato de ensinar, sobre o papel da universidade, sobre o destino da ciência etc.

A retomada do movimento veio com a mediação entre expectativas individuais e propostas políticas: ao lado da luta por mais verbas para a educação, melhor nível de ensino, liberdade curricular etc., que importam em possibilitar melhor cumprimento de expectativa de ascensão social, o movimento reivindicava a "redemocratização" do país, a anistia, o fim das leis de exceção, convocação de uma assembleia nacional constituinte, etc. Havia mesmo um conjunto de alunos que argumentavam que o atendimento às reivindicações de mais verbas para a educação, melhor nível de ensino, democratização interna da Universidade, dentre outras, só seria possível com a redemocratização do país.

A luta por mais vagas, ensino público e gratuito, melhor nível de ensino (a crise limita emprego aos mais preparados, mas nem sempre), que permitissem possibilidade de formatura em nível superior e ascensão social, coexistiam com a esperança de um modelo social com melhor distribuição de renda, democrático, com possibilidade de participação de setores organizados da sociedade. É evidente que setores estudantis minoritários já se expressavam em torno da bandeira de lutas de "uma sociedade socialista". A ênfase do movimento, pela constituinte, pela anistia, fim de leis de exceção, liberdade de organização, universidade autônoma, etc., indica um desejo (pelo menos na conjuntura de então) de viver numa sociedade regulada democraticamente e na qual a Universidade tivesse voz e vez.

\section{A RECONSTRUÇÃO DA UNE}

Em 29 e 30 de maio de 1979 foi reconstruída a UNE, apesar das declarações oficiais do governo, em 15 de maio, de que o Congresso seria ilegal. O Congresso de reconstrução da UNE (XXXI Congresso) realizou-se em Salvador, Bahia, e do mesmo participaram 2.304 delegados estudantis de todos os Estados do Brasil.

O Congresso fora precedido de debates e de exposição de ideias pelas diversas "correntes de pensamento" ("tendências") do movimento estudantil.

A Liberdade e Luta (LIBELU) entendia que a UNE seria "junto às lutas do estudante, o nosso maior instrumento de combate contra a ditadura militar" ${ }^{28}$ e propunha a aliança estudantil-operária-camponesa para mudar o país. Já a tendência Viração (Caminhando) advogava que a UNE encaminhasse "as lutas mais gerais, como a defesa da Amazônia, a anistia ampla, geral e irrestrita e [...] lutar por um governo amplamente democrático, que convoque uma assembleia nacional constituinte soberana e livremente eleita". "Sangue Novo" defendia a unificação do ME em torno de bandeiras gerais e que a UNE deveria atuar como reforço "na luta pela liberdade do movimento do povo brasileiro". A alternativa socialista para o ME era proposta pelo movimento "Combate", que via a UNE como reflexo do avanço das lutas dos trabalhadores e da necessidade de uma unificação nacional das lutas estudantis. Defendia a 
[...] organização pela base do ME, em cima da luta contra a política educacional do governo, caracterizando-a como necessidade da burguesia a nível educacional, e transformando o ME numa força auxiliar dos trabalhadores na luta contra a exploração e opressão.

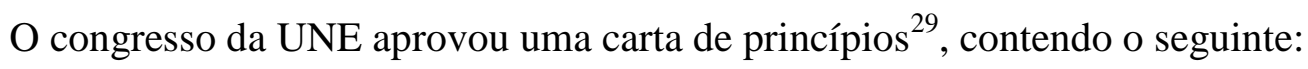

1) A UNE é uma entidade máxima e representativa dos estudantes brasileiros na defesa de seus interesses e direitos; 2) A UNE é uma entidade livre e independente, subordinada unicamente ao conjunto dos estudantes; 3) a UNE deve pugnar em defesa dos interesses e direitos dos estudantes, sem qualquer distinção de raça, cor, nacionalidade, sexo ou convicção política, religiosa ou social; 4) a UNE deve prestar solidariedade à luta de todos os estudantes e entidades estudantis do mundo; 5) a UNE deve incentivar e preservar a cultura nacional e popular; 6) A UNE deve lutar pelo ensino voltado para os interesses da população brasileira, de forma gratuita em todos os níveis; 7) A UNE deve lutar contra todas as formas de opressão e exploração e prestar irrestrita solidariedade à luta dos trabalhadores do mundo inteiro.

Estabeleceu o Congresso de reconstrução da UNE um conjunto de lutas imediatas:

1. Contra o ensino pago; 2. Por mais verbas para a educação; 3. Pela anistia, ampla, geral e irrestrita; 4. Pela filiação de entidade de base (diretórios e centros acadêmicos) à UNE; 5. Por uma Assembléia Nacional Constituinte, soberana e livremente eleita; 6. Pela defesa da Amazônia.

Persiste no congresso de reconstrução a associação entre lutas de interesse dos estudantes propriamente ditos e lutas de interesse geral, como que a indicar que as expectativas individuais e sociais se casam e que o movimento estudantil organizado não abandonou a perspectiva das chamadas "lutas gerais".

Reconstruída, a UNE procurou, através de sua diretoria, sistematizar sua atuação ${ }^{30}$. Em 1970, a UNE realizou o Seminário Nacional de Educação. Os congressos seguintes não alteraram substancialmente as propostas. Assim é que no XXXII Congresso,

[...] a discussão mais longa e detalhada foi acerca da calamitosa situação em que se encontra a Universidade no país. Apresentamos um conjunto de propostas no sentido de levarmos adiante nosso questionamento e nossa luta por uma universidade que atenda nossos interesses.

O congresso aprovou lutas contra o repasse de aumento de salários de professores para as anuidades; percentual de $12 \%$ do Orçamento da União destinados ao ensino; contra aumentos extorsivos de anuidades; suplementação imediata de verbas para o ensino público superior; democratização da universidade.

Boletim ${ }^{31}$ afinado com o presidente eleito no XXXI Congresso destacou o pensamento da diretoria acerca do país desejado pelos diretores da UNE:

O nosso posicionamento é por um Brasil melhor, um Brasil do povo e não dos seus algozes. Um Brasil onde o pão de cada dia seja um direito popular e não a impunidade dos terroristas e governantes. Onde o centro de decisão esteja nas mãos dos brasileiros e não dos magnatas dos grupos 
econômicos. E para isto não existem dois caminhos. Só existe o caminho da substituição deste governo anti-operário e anti-popular por um governo representativo dos anseios do povo e dos trabalhadores brasileiros, um governo que convoque uma Assembleia Constituinte onde o povo possa elaborar as leis que atendam às suas reivindicações. Uma assembléia eleita com liberdade para todas as correntes políticas, para todos os partidos, inclusive aqueles que hoje se encontram na ilegalidade, uma Assembleia Constituinte que seja a expressão da soberania popular sobre os destinos do Brasil.

Os estudantes qualificaram a Universidade como alienante e autoritária e acentuaram $^{32}$ :

A política oficial é de fazer recuar e derrotar em todas as frentes possíveis o ensino público e gratuito, importante conquista da luta geral pela democratização da universidade brasileira. Não é este o único ataque que a orientação do governo imprime à educação. Servir à política econômica de dependência é a incumbência reservada à Universidade pela ditadura.

Com isso desmoronam como castelos de areia os sonhos daqueles que procuram a Universidade para contribuir na solução dos problemas do país. Da mesma forma frustram-se as nossas expectativas de aperfeiçoamento científico e intelectual.

Isto porque às classes dominantes interessa que nos transformemos em reprodutores fiéis de sua ideologia e em instrumentos para a manutenção da ordem econômica atual.

Numa palavra, a Universidade é elitista. E para continuar sendo assim, ela tem de ser autoritária, discriminatória e alienada.

Estas características se manifestam no abandono da pesquisa científica adequada às necessidades do país, enquanto nos ensinam o simples manejo de uma tecnologia importada.

A predominância de cursos e currículos divorciados da nossa realidade e as dificuldades que a centralização do poder cria para a sua alteração por iniciativa da comunidade universitária, finaliza o quadro da universidade brasileira hoje.

Não é esta a Universidade que corresponde aos anseios dos estudantes e do povo brasileiro.

Fica evidente, nas publicações estudantis da época, a preocupação em combinar a atividade dos estudantes com a atividade política, ou como diz um daqueles escritos:

Colegas, os estudantes junto com o povo brasileiro tem de se colocar à cabeça da luta contra o governo dos generais. Temos de estar na primeira linha de combate contra o adiamento da eleição de 1980. Temos de barrar a escalada terrorista que as forças mais retrógradas da nação desencadeiam, como bombas em bancas, atentados pessoais, agressões, etc. Mas antes de mais nada, não devemos ter ilusões de que o mesmo governo que é cúmplice destes atentados, e nada faz para descobrir os culpados, possa vir a garantir as liberdades democráticas no país [...]. Não 
se pode conquistar a liberdade nos marcos do atual regime. A conquista da mais ampla liberdade política exige e pressupõe a derrubada do governo militar.

Não se encontram maiores diferenciações, como foi dito, mas "plataformas de luta", exceto quanto a "palavras de ordem" de natureza política. Neste sentido, o ano de 1984, foi de grande polarização. Não se tratou apenas de um ano em que as universidades autárquicas federais ficaram quase três meses em greve, paralisadas por professores e funcionários, que exigiram aumento de salários, mais verbas para o ensino, mais liberdade, eleição direta para reitor etc., mas foi também o ano da sucessão presidencial. Grosso modo, os estudantes defenderam eleições diretas para Presidente da República, porém à medida que as elites brasileiras conseguiram desmobilizar as grandes manifestações por eleições diretas e à medida que foi derrotada a "Emenda Dante Oliveira", surgiu a posição alternativa de apoio a um candidato único das oposições, submetido ao colégio eleitoral. Para discutir a posição do estudantado foi convocado o V Conselho Nacional de Entidades de Base (V CONEB) ${ }^{33}$ e o XVII Conselho Nacional de Entidades Gerais (XVII CONEG), respectivamente para reunir-se em Vitória da Conquista, Bahia, e Rio de Janeiro, RJ. Os estudantes afinados com o PC do B, PCB, PMDB decidiram-se por apoiarem um candidato único das oposições, mesmo via colégio eleitoral, enquanto que os grupos de esquerda abrigados no PT e dissidências do PCB pregavam o repúdio ao Colégio Eleitoral e a retomada das lutas por eleições diretas.

O V CONEB repudiou o colégio eleitoral e reafirmou a luta por eleições diretas.

O XXXVI Congresso ${ }^{34}$ da UNE (1984) ainda foi bastante marcado por questões gerais da luta política contra o regime militar e posicionamentos quanto à candidatura de oposição à sucessão presidencial (Chapa Tancredo-Sarney), momento em que o tipo de transição para o "regime democrático" foi questionado pelos estudantes. Alguns denunciavam o caráter conservador da transição proposta, outros acreditavam ser positiva a transição, principalmente se o candidato oposicionista assumisse a defesa de um programa de governo popular.

Entretanto, o encaminhamento e a realização do XXXVI Congresso não deixaram de apresentar posicionamentos quanto à universidade. Uma tendência, em ascensão no movimento estudantil, via PT, por exemplo, pontificava:

Mas nossa tarefa não é esperar, e sim ir forjando nas lutas de hoje, contra o poder autoritário estabelecido, dentro e fora das escolas, a nova Universidade e a nova sociedade.

Nesse sentido, é da maior importância impor derrotas decisivas à política do MEC e do regime militar. E avançar firmemente na luta pelo ensino público gratuito. Defendendo as poucas Universidades públicas e "gratuitas" e a pouca pesquisa nelas realizada e exigindo sua ampliação. Impedindo os aumentos das anuidades e a evasão escolar, com nenhum aluno fora da escola, na perspectiva de federalização das faculdades pagas. Lutando pela transformação do crédito educativo em bolsas não reembolsáveis, com a anistia aos devedores. Exigindo mais verbas para a educação com a aplicação imediata da emenda João Calmon. Lutando pelo fim das taxas e sobretaxas, pela revogação da portaria 62/82 dos RUs e pelo pleno funcionamento dos restaurantes, pela manutenção e ampliação da assistência estudantil. Reivindicando, ao lado dos professores e funcionários, salários justos e melhores condições de ensino. Conquistando eleições diretas para reitor e todos os cargos de 
direção e a abertura de todos os livros-caixa. Consolidando 1/5 e lutando pela paridade nos órgãos colegiados. Exigindo o fim dos órgãos de informação e segurança, as assessorias especiais, o fim dos regimentos repressivos nas escolas, o reconhecimento da UNE e de todas as entidades estudantis. Lutando, enfim, decididamente, porque este é o caminho a ser seguido.

O movimento estudantil organizado teve continuidade, porém os congressos da $\mathrm{UNE}^{35}$ gradativamente deixaram de ter a expressão de que antes eram dotados. A palavra crise passou a ser ouvida nos ambientes de disputa de entidades estudantis, tratava-se da crise do movimento estudantil, ainda não bem diagnosticada.

\section{CRISE. CRISE?}

A divisão política no seio dos estudantes combativos chegou a um nível de profundidade só visto nos momentos mais radicais de 1968/1969 (em que, no entanto, a luta contra a ditadura unia a todos). O XXXIX Congresso, realizado em 7, 8, 9 e 10 de outubro de 1988, em São José dos Campos, São Paulo, com mais de 3.000 delegados, presenciou acirrada disputa entre o PC do B e correntes do PT. "Viração" (PC do B) acusou a diretoria da UNE de haver adiado o prazo de inscrições para beneficiar-se e de aprovar credenciamento de acordo com seu interesse. O PT, por outro lado, acusava "Viração" de querer impedir a realização do Congresso, porque estava em minoria, e argumentava que aquela tendência havia aceitado critérios para a comissão de credenciamento. Estudantes ligados ao PCB, PSB, PSDB e PDT tentaram articulação exigindo o prosseguimento do congresso, que teve continuidade com uma série de incidentes, causados por divergências políticas. Instalada a plenária do Congresso, já no dia 10 (segunda-feira) os estudantes de "Viração" retiraram-se - sob condenação das demais correntes. $\mathrm{O}$ grupo hegemonizado pelo PT venceu as eleições.

O XXXIX Congresso da UNE decidiu pelo desencadeamento de campanha contra o governo Sarney, apoio aos movimentos dos professores, denúncia de caráter conservador da Constituição do País, dentre outras resoluções.

O que é inegável, no entanto, é que a UNE, UEES, DAS etc. já não motivam tanto os estudantes como antes e não se vê estranhamento maior do ME organizado entre a massa estudantil. A crise do ME tornou-se visível para muitos. As propostas do movimento têm sido repetitivas e as formas de atuação não conseguem sequer manter a imagem das entidades estudantis presentes entre os estudantes e a sociedade. Próximo do XL Congresso, a UNE está com dificuldades de encontrar uma saída para rearticular o movimento.

William Alberto Campos, vice-presidente da UNE, em artigo publicado no Jornal do Brasil, Caderno B - Especial, de 6.11.88, chega a dizer que "mantida somente por simpatizantes de partidos políticos, a União Nacional dos Estudantes acaba por não representar ninguém ${ }^{36}$.

É também Campos, no mesmo artigo quem expressa ${ }^{37}$ :

Sejamos honestos: na prática quem tem sido o real presidente da entidade é o cantor e compositor Renato Russo, que obrigou os estudantes a questionarem o país no qual vivem entoando o rock “que país é este?” um dos hinos da juventude. Nesse momento, os estudantes vivem um grande impasse entre o movimento das ruas, de idéias e de rebeldia contra a 
estática do "aparelho", do vanguardismo e da negação da modernidade. É importante não perder de vista a ambigüidade própria do movimento estudantil. Ele oscila, frequentemente, entre uma recusa radical da universidade, que se expressa através do "saco cheio", uma insatisfação generalizada, social e intelectualmente e um reformismo prático que critica tanto os conteúdos quanto a forma de ensino, aspirando por uma universidade crítica com debates e grupos de estudos. O objetivo do movimento estudantil é o de permitir a liberação da palavra para que a crítica da sociedade possa se expressar e ser vivida.

Há quem, como o professor Arthur Ribeiro Neto, atribua a crise da UNE à cooptação das lideranças pelos partidos, fato que desloca a fonte de legitimidade dos discursos dos estudantes propriamente ditos para a "verdade revolucionária" de que os partidos se dizem portadores. Acredita Arthur Ribeiro Neto que

[...] o privilégio de saber para que servia, qual era o sentido da ação dos estudantes deixa de ser um problema das discussões dos coletivos estudantis, das assembléias, reuniões abertas, salas de aulas e corredores onde todos podiam opinar, e emigra para um estamento político que, por definição, é detentor do poder de refletir e de saber; é o único com direito à verdade.

Em outro passo, Arthur Ribeiro Neto ${ }^{38}$ denuncia "a conversão do estudante em incompetente político pelas suas próprias lideranças" e assinala:

[...] creio, é um acontecimento decisivo na ruptura da identidade estudantil. E a recusa das pessoas a esta condição representa uma nova forma de romper a sedução de um corpo positivo, adamantino. Ser estudante tornou-se isto: ser o corpo, a carne bruta para que uma aristocracia aja e pense em seu nome, para que busque em seu nome os objetivos dela. Este processo foi tão profundo que as próprias entidades são percebidas como partes deste estamento aristocrático. O movimento estudantil hoje é o movimento deste estamento, ao qual as pessoas que freqüentam a universidade recusam a legitimidade que a existência de um corpo de estudantes daria. ${ }^{39}$

As críticas mais comuns no meio acadêmico versam sobre a desatualização da UNE. Há visão "funcionalista" que vê na UNE de anos anteriores um "instrumento" da sociedade, por estar desejado como canal de expressão de insatisfação, em momentos de repressão dentro da sociedade civil ${ }^{40}$. Hoje, há inúmeros canais de expressão, pelo que a UNE deixou de funcionar como canal privilegiado. Entretanto, isso não é uma explicação satisfatória, mesmo porque antes de 1964 havia o mesmo grau de liberdade formal que hoje e a UNE esteve em ascensão, apesar das múltiplas propostas dentro do movimento. Mais importante que esta explicação é a "institucionalização" das lutas, que vêm sendo perseguida insistentemente pela burguesia, fazendo drenar as insatisfações por canais dentro do Estado.

Como quer que seja, a crise está sendo "pensada" e pensar a crise é o início do novo para o movimento estudantil hoje, na proximidade do $40^{\circ}$ Congresso da UNE. 


\section{REFERÊNCIAS}

CUNHA, Luís Antonio Rodrigues da. O milagre brasileiro e a política educacional. Argumentos, Paz e Terra, ano 1, n. 2, nov. 1973.

LAMOUNIER, Bolívar e outros. "Os partidos e as eleições no Brasil”. São Paulo: Paz e Terra, 1974. IBRAHIM, José. “Comissões de fábricas”. São Paulo: Global, 1986.

LIMA, Haroldo; ARANTES, Aldo. História da ação popular - da JUC ao PC do B. 2. Ed. Alfa-Ômega, 1984.

MARTINS, Carlos Estevam. "História do CPC" “Arte em Revista", São Paulo: Kairós Livraria, n. 3, p. 77-87, mar. 1980).

NASCIMENTO, Antonio Dias "Organização de base: reinvenção da participação popular”. 1985. Tese (Mestrado) - Universidade Federal da Bahia, Faculdade de Filosofia e Ciências Sociais, Salvador.

REIS FILHO, Daniel Aarão; SÁ, Jair Ferreira de. Imagens da revolução. RS: Marco Zero, 1985.

\section{Notas}

\footnotetext{
* Professor de Direito da Universidade Estadual do Sudoeste da Bahia; Mestre em Memória: Linguagem e Sociedade. Doutorando pelo Programa de Pós-Graduação em Memória: Linguagem e Sociedade UESB; Integrante do Museu Pedagógico da UESB e do HISTEDBR-GT Bahia.

** Orientador - Professor Doutor em Educação pela UNICAMP, professor de História da Educação na Faculdade de Educação da UNICAMP e pesquisador vinculado ao grupo de Pesquisa HISTEDBR É Professor visitante do Programa de Mestrado e Doutorado em Memória, Linguagem e Sociedade da Universidade Estadual do Sudoeste da Bahia.

${ }^{1}$ Introdução apenas para localizar o tema. Dispensável diante da bibliografia existente, principalmente Arthur J. Poerner ("O Poder Jovem").

${ }^{2}$ Sobre o CPC, vide, dentre outros: "História do CPC" (depoimento de Carlos Estevam Martins. "Arte em Revista", São Paulo: Kairós Livraria, n. 3, p. 77-87, mar. 1980).

${ }^{3}$ UNE Volante: grupo de 20 a 25 membros da UNE que percorreu o país (várias capitais), acompanhado do CPC.

${ }^{4} 1^{\circ}$ Congresso Camponês - Belo Horizonte, 1961.

${ }^{5} 1^{\circ}$ Seminário Nacional de Reforma Universitária (SNRU), Salvador, 20 a 27 de maio de 1961.

Greve de 1/3 (junho de 1962) - por reivindicação de participação dos estudantes nos colegiados de faculdades e de universidades.

$2^{\circ}$ SNRU - Curitiba, 17 a 24 de março de 1962.

Sobre tais assuntos, pode-se ler "História da ação popular - da JUC ao PC do B", especialmente o $1^{\circ}$ capítulo da obra de LIMA, Haroldo; ARANTES, Aldo. História da ação popular - da JUC ao PC do B. 2. Ed. Alfa-Ômega, 1984.

Sobre os diversos grupos políticos de esquerda, especialmente seus programas, a obra básica continua sendo REIS FILHO, Daniel Aarão; SÁ, Jair Ferreira de. Imagens da revolução. RS: Marco Zero, 1985.

${ }^{6}$ Grupo da Ação Católica - chegou a dirigir a UNE no período.

${ }^{7}$ Criada pela "esquerda" da JUC.

${ }^{8}$ A Lei Suplicy de 27.10.1964 extinguiu a UNE e as UEES. A lei 4464, editada em 6.11.1964 proíbe atividades políticas das organizações estudantis.

${ }^{9}$ Sobre o IPES e sobre reportagens referidas, inclusive autora, vide DREIFUSS, René Armand. "1964: a conquista do Estado - ação política, poder e golpe de classe". 1981. Especialmente carta de Sônia Maria Saraiva ao SNI, no apêndice O (muito reveladora).

${ }^{10}$ A posição de José Dirceu parece apresentar um laivo funcionalista. O pequeno depoimento pode ser lido em "UNE faz história". In: Manual do Estudante. Abril: 1989. p. 58.
} 
${ }^{11}$ Sobre AP e ME $1^{\circ}$ de maio vide LIMA, Haroldo; ARANTES, Aldo. História da ação popular - da JUC ao PC do B. 2. Ed. Alfa-Ômega, 1984 e REIS FILHO, Daniel Aarão; SÁ, Jair Ferreira de. Imagens da revolução. RS: Marco Zero, 1985.

${ }^{12}$ AP chegou a formular tática de "aliança-operária-estudantil-camponesa". Sobre os programas vide REIS FILHO, Daniel Aarão; SÁ, Jair Ferreira de. Imagens da revolução. RS: Marco Zero, 1985.

${ }^{13}$ Sobre o período, há muito escritos.

Sobre economia, dentre outros: RANGEL, Ignácio. "Economia: milagre e anti-milagre". TAVARES, Maria da Conceição. "Da substituição das importações ao capitalismo financeiro". BRUM, Argemiro J. "O desenvolvimento econômico brasileiro". EVANS, Peter. "A tríplice aliança". SINGER, Paul. "Dominação e desigualdade". MANTEGA, Guido; MORAES, Maria. "Acumulação monopolista e crises no Brasil". OHLWEILER, Otto Alcides. "Evolução sócio-econômica do Brasil", etc.

Sobre política, dentre outros: ALVES, Maria Helena Moreira. "Estado e oposição no Brasil (1964-1984)". CARDOSO, Fernando Henrique. "O modelo político brasileiro". DROSDOFF, Daniel. "Linha dura no Brasil". GORENDER, Jacob. "Combate nas trevas". STEPAN, Alfred. "Os militares na política". Obra coletiva "Brasil nunca mais", etc.

${ }^{14}$ Vide CUNHA, Luís Antonio Rodrigues da. O milagre brasileiro e a política educacional. Argumentos, Paz e Terra, ano 1, n. 2, nov. 1973.

${ }^{15}$ Há quem conteste a afirmação de Luís Antonio Rodrigues da Cunha, pois mesmo durante o "pacto populista" o número de vagas no ensino superior estava em crescimento (vide artigo em Encontros com a civilização brasileira). Pode-se argumentar, também, que a ditadura "abriu" espaço para setores de classe média, com a expansão econômica, que já estava sem alternativa diante da crise de início dos anos 60 . A abertura de possibilidades, no entanto, foi conjuntural e expressou-se nos campos necessários para a nova fase de acumulação industrial (produção capitalista) proposta pelos militares. De qualquer maneira, há relação entre as prioridades da política militar (que passou a drenar recursos para áreas de respostas mais imediatas) e a degradação da Universidade, tendo como consequência uma série de demandas estudantis.

${ }^{16}$ Diante disso, observam-se as expectativas movimentarem-se. Houve ampla discussão dos estudantes sobre a "realidade brasileira" e a situação da universidade,

${ }^{17}$ Estou relatando "de memória", mas, no geral, essas eram as posições dos partidos de esquerda no movimento estudantil, especialmente do PCB (que apresentava proposta mais articulada, porém acusada de reformista, de conciliação com o regime / o PCB aceitava o "diálogo com o ministro"), o POB (dissidência da POLOP), o PC do B, a AP... O PC do B passou da proposta de "Universidade Popular Livre e Democrática" para simples "Não à Reforma Universitária da Ditadura" (no caso, o PC do B propôs uma articulação estudantil - o Movimento de Unidade e Ação (MUA)).

${ }^{18}$ É bom ler "A volta da UNE" " "Memorex".

${ }^{19}$ Vide coletânea de discursos de Francisco Pinto (MDB).

${ }^{20}$ Aqui, esboça-se tentativa de compreender a retomada do movimento a partir da "crise do milagre". Esta crise é, efetivamente, um referencial. A partir dela a "oposição liberal" passa a rearticular-se, Geisel fala em distensão lenta, gradual e segura etc. Em 1974, o MDB ganharia muitos votos ... Setores da burguesia descolavam do regime, pois o "milagre" começava a deixar de dar frutos. Os trabalhadores, aos poucos, rearticulavam comissões de fábricas e os estudantes não eram alheios às mudanças.

Para a "crise do milagre", vide especialmente o último capítulo, SINGER, Paul. "A crise do milagre: interpretação critica da economia brasileira". Paz e Terra.

${ }^{21}$ Índices de inflação: $1973=15,4 \% ; 1974=34,5 \%$.

${ }^{22}$ Para estudo das eleições de 1974, vide LAMOUNIER, Bolívar e outros. "Os partidos e as eleições no Brasil". São Paulo: Paz e Terra, 1974. (Carlos Estevam Martins, no capítulo "O Balanço da Campanha" coloca em devidos lugares o significado da Vitória do PMDB).

${ }^{23}$ Vide, dentre outros, IBRAHIM, José. “Comissões de fábricas". São Paulo: Global, 1986.

${ }^{24}$ Vide, para estudo da "participação popular, via Igreja", NASCIMENTO, Antonio Dias "Organização de base: reinvenção da participação popular". 1985. Tese (Mestrado) - Universidade Federal da Bahia, Faculdade de Filosofia e Ciências Sociais, Salvador.

${ }^{25}$ Em Vitória da Conquista, em 28.03.68, estudantes realizaram homenagem a Edson Luís, no recinto da Câmara de Vereadores. Para Vitória da Conquista, vide informação diminuta em MEDEIROS, Ruy. "A questão democrática em Vitória da Conquista". 1979. (mimeografado).

${ }_{26}$ Alexandre Vanuchi Leme, Presidente do DA de Geologia, SP, assassinado em 1973.

${ }^{27}$ Aí cabe toda a meditação / dados que vocês levantaram sobre a Universidade - Muito bom colocar, na perspectiva de todo um movimento emergencial, o item 6 do estudo de vocês ( $\mathrm{O}$ Compromisso da Universidade.

Vide estudo de Cassimiro, na revista "Educação e Sociedade". 
${ }^{28}$ Caracterização a partir de entrevista de membros das diversas tendências ao Jornal da Bahia (Vide: $\mathrm{O}$ governo a considera ilegal. Jornal da Bahia, caderno 2, p. 1, 20 maio 1979. Agora veja o que os estudantes acham da UNE).

${ }^{29}$ Vide - "A volta da UNE". Carta de princípios e lutas imediatas, além de informe geral sobre o congresso em: "BEBA". Boletim dos Estudantes da Bahia. Diretório Central dos Estudantes da UFBA, jun. 1979.

${ }^{30}$ Vide boletim "Vote Voz Ativa - UNE".

${ }^{31}$ Boletim Voz Ativa, 1970.

${ }^{32}$ Vide Congresso da UNE - Pontos para discussão (Boletim publicado pela UNE, 1970).

${ }^{33}$ Vide documentos anexos sobre o CONEB (Vitória da Conquista, 3, 4 e 5 de agosto de 1984).

${ }^{34}$ XXXVI Congresso - dias 26, 27, 28 de outubro de 1984.

${ }^{35}$ É bom lembrar: 1978 - Revogação dos decretos leis 228 e 477 (29 de novembro) - aprovação pela comissão de Justiça da Câmara dos Deputados do projeto de lei que permite a reorganização da UNE (29.11) 1983 - Brizola, em 21 de julho, cede à UNE um imóvel para instalação provisória da UNE, no Rio de Janeiro. - Revogação da Lei do Boi, em 18 de novembro de 1985 (Lei que previa reserva de 50\% de vagas em escolas de agricultura e veterinária para agricultores e filhos destes residentes em zonas rurais, e $30 \%$ para os residentes em cidades (também filhos de agricultores).

36 “A UNE não existe". JB, Caderno B, 6.1.88, reproduzido em "Movimento Estudantil Hoje", "Revista" publicada pela Vice-presidência Nordeste III da Une.

${ }^{37}$ Idem, ibidem.

${ }^{38}$ Vide: "UNE um laço que não nos une mais", reproduzido em "Revista" da UNE - NE III.

A análise de Arthur Ribeiro Neto centra-se em três núcleos:

a) Desatualização da UNE (a UNE não conseguiu incorporar-se às necessidades de um novo tempo, na modernidade);

b) compartimentação (ruptura) entre entidades/lideranças diante da massa estudantil (as decisões não são tomadas a partir dos estudantes, mas nos espaços dos partidos políticos);

c) A UNE não superou o populismo (mesmo 1968 foi momento de radicalização do populismo).

Trata-se de tese "instigante", porém que merece alguma crítica e relativização.

${ }^{39}$ Idem, ibidem.

${ }^{40}$ Vide opinião de José Dirceu, em "Guia do Estudante”, já citado.

Uma pesquisa de campo, desde que o entrevistador consiga que os estudantes não mascarem as respostas às entrevistas, pode ajudar no sentido de dar indicativos ao ME para romper o distanciamento entre os estudantes e o "aparelho estudantill".

Recebido em abril-2014

Aprovado em maio-2014 